\title{
Article \\ Glycerol Valorization towards a Benzoxazine Derivative through a Milling and Microwave Sequential Strategy
}

\author{
Miguel Ángel Torres-Pastor ${ }^{1,+}$, Claudia Espro ${ }^{2, *},+\left(\mathbb{C}\right.$, Maurizio Selva $^{3}{ }^{(0)}$, Alvise Perosa $^{3}{ }^{(0)}$, \\ Antonio A. Romero Reyes ${ }^{1}\left(\mathbb{D}\right.$, Sameh M. Osman ${ }^{4}(\mathbb{D})$, Rafael Luque ${ }^{1,4,5, *(\mathbb{D})}$ and Daily Rodríguez-Padrón ${ }^{2, *}$ (D) \\ 1 Grupo FQM-383, Departamento de Química Orgánica, Universidad de Cordoba, 14014 Cordoba, Spain; \\ m.a.torres1998@hotmail.es (M.Á.T.-P.); qo1rorea@uco.es (A.A.R.R.) \\ 2 Dipartimento di Ingegneria, Università di Messina, 98100 Messina, Italy \\ 3 Dipartimento di Scienze Molecolari e Nanosistemi, UniversitàCa' Foscari di Venezia, 30123 Venezia, Italy; \\ selva@unive.it (M.S.); alvise@unive.it (A.P.) \\ 4 Chemistry Department, College of Science, King Saud University, P.O. Box 2455, Riyadh 11451, Saudi Arabia; \\ smahmoud@ksu.edu.sa \\ 5 Scientific Center for Molecular Design and Synthesis of Innovative Compounds for the Medical Industry, \\ People's Friendship University of Russia (RUDN University), 117198 Moscow, Russia \\ * Correspondence: espro@unime.it (C.E.); q62alsor@uco.es (R.L.); dailydggs@gmail.com (D.R.-P.) \\ $\dagger$ These authors have contributed equally to this work.
}

check for updates

Citation: Torres-Pastor, M.Á.; Espro, C.; Selva, M.; Perosa, A.; Romero

Reyes, A.A.; Osman, S.M.; Luque, R.; Rodríguez-Padrón, D. Glycerol Valorization towards a Benzoxazine Derivative through a Milling and Microwave Sequential Strategy. Molecules 2022, 27, 632. https:// doi.org/10.3390/molecules27030632

Academic Editors: Kamelija Zarkovic and Neven Zarkovic

Received: 13 December 2021

Accepted: 17 January 2022

Published: 19 January 2022

Publisher's Note: MDPI stays neutral with regard to jurisdictional claims in published maps and institutional affiliations.

Copyright: (C) 2022 by the authors. Licensee MDPI, Basel, Switzerland. This article is an open access article distributed under the terms and conditions of the Creative Commons Attribution (CC BY) license (https:// creativecommons.org/licenses/by/ $4.0 /$ )

\begin{abstract}
Glycerol and aminophenol intermolecular condensation has been investigated through a milling and microwave-assisted sequential strategy, towards the synthesis of a benzoxaxine derivative. Mechanochemical activation prior to the microwave-assisted process could improve the probability of contact between the reagents, and greatly favors the higher conversion of aminophenol. At the same time, following a mechanochemical-microwave sequential approach could tune the selectivity towards the formation of a benzoxazine derivative, which could find application in a wide range of biomedical areas.
\end{abstract}

Keywords: milling; microwave irradiation; glycerol valorization; benzoxazine derivative

\section{Introduction}

The current depletion of fossil fuels, together with the increase in energy consumption, as well as the global warming trends and their consequences on the environment and human safety, have promoted the development of more sustainable protocols, according to green chemistry principles [1-3]. In this sense, biorefineries have emerged as a highly promising option for the environmentally friendly preparation of chemicals, fuels, and materials [4-9]. For instance, biodiesel is a well-known biofuel obtained either from animal fats or vegetal oils, through a transesterification reaction under alkaline conditions $[10,11]$. Such well-known processes also give rise to the formation of glycerol as a subproduct. In order to fully ensure the sustainability and economic viability of the biodiesel production, the valorization of glycerol must be carried out [12].

In this regard, several strategies have been proposed to date, including the preparation of solketal [13], acrolein [14], cyclic acetals [15], glycidol [16], glycerol carbonate [17], diacetins [18], and mono- and polyesters/ethers [19], among others. Furthermore, the use of glycerol has been also reported for the synthesis of aryloxypropanediols with pharmaceutical activity, via reaction with several phenol derivatives, such as ortho-methoxyphenol, ortho-methylphenol, and para-chlorophenol, to name a few [20]. The desired products have been obtained in good yields; however, the reactions require long reaction times of between 12 and $28 \mathrm{~h}$ under conventional heating conditions, depending on the phenolic compound. The synthesis of aryloxypropanediols has been mainly reported by nucleophilic attack of phenols and glycidol, 1-chloroglycerol, or epichlorohydrin. The use of the aforementioned chemicals has several disadvantages, mainly related to their toxicity. Therefore, 
the use and valorization of glycerol, with the in situ formation of glycerol carbonate, constitute a green synthetic pathway. Moreover, reaction with other phenolic compounds, such as 2-aminophenol for the formation of benzoxazine derivatives, have scarcely been investigated. Importantly, benzoxazine heterocyclic products, which are non-steroidal progesterone receptor agonists, could find a broad range of applications in biomedicine, as antidepressant, antiangiogenic, antidiabetic, hypolipidemic, and anticancer agents. In addition, such compounds possesses antiplatelet aggregation activity [21].

With the aim of investigating the reaction of glycerol with 2-aminophenol, and to decrease reaction times in comparison with conventional approaches reported for the reaction of glycerol with other phenolic compounds, microwave technologies could be a highly valuable option. It is worth remarking that microwave technologies could improve the heat transfer of a process, as well as reduce reaction times and give rise to novel chemical behaviors that are different from those observed under conventional conditions [22,23].

In addition to microwave technologies, the use of mechanochemistry for organic synthesis has sparked the attention of the scientific community in recent years [24-26]. Even though mechanically induced reactions have been carried out since the 4th century BC, the number of publications on mechanochemistry only started increasing approximately 20 years ago. Thus far, mechanochemistry has been broadly employed for the synthesis of advanced nanomaterials [27], for the extraction of nutraceuticals, and, even more recently, for organic synthesis, including the preparation of active pharmaceutical ingredients (APIs). Very interesting studies have focused on the employment of this methodology for SuzukiMiyaura cross-coupling reactions [28], the synthesis of peptides [29], and even of DNA fragments [30], to name some examples. Remarkably, mechanochemistry is a highly sustainable, simple, and reproducible approach [31].

A sequential mechanochemical and microwave-assisted strategy has been proposed for the valorization of glycerol through reaction with 2-aminophenol, under solvent-free conditions (Figure 1). For comparison, several strategies have been considered, including a mechanochemically assisted approach, a microwave-assisted strategy, and a sequential mechanochemically activated and microwave-assisted methodology.

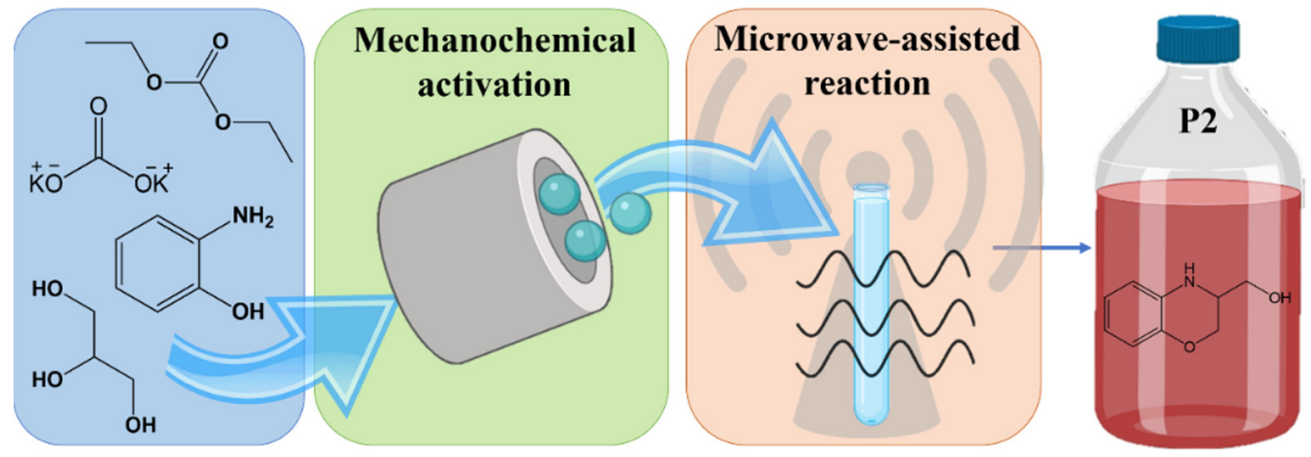

Figure 1. Illustrative representation of the reaction of 2-aminophenol with glycerol through a combined mechanochemical and microwave-assisted approach.

\section{Results and Discussion}

As a first approximation, the suitability of mechanochemistry for the condensation reaction of glycerol and 2-aminophenol was studied. A set of experiments was performed considering glycerol equivalents, milling time, and speed. However, low to negligible conversion values were achieved (Table 1, Entry 1), even when carrying out the reactions at a relatively high speed and over a prolonged time (Table 1, Entry 2, Table S1 Entry 10-13). These experiments indicated that, for the studied reaction and under the employed conditions, mechanochemical methods did not promote progress of the reaction, but, most probably, only the homogenization of the reaction mixture improved the probability of contact between the reagents. In addition, the influence of liquid-assisted grinding was 
explored by performing the reaction after adding $1 \mathrm{~mL}$ of acetone as a solvent (Table S1, Entry 14-17), also resulting in no significant improvement.

Table 1. Performance of reactions of 2-aminophenol and glycerol, employing $\mathrm{K}_{2} \mathrm{CO}_{3}$. Quantification analysis was performed from GC-MS results.

\begin{tabular}{|c|c|c|c|c|c|}
\hline Entry & $\begin{array}{l}\text { Mechanochemical } \\
\text { Conditions }\end{array}$ & $\begin{array}{c}\text { Microwave } \\
\text { Conditions/Conventional } \\
\text { Heating }\end{array}$ & $C *(\%)$ & $\mathrm{S} * *(\mathrm{P} 2, \%)$ & $Y^{* * *}(\%)$ \\
\hline 1 & $60 \mathrm{~min}, 350 \mathrm{rpm}$ & - & $<1$ & $<1$ & $<1$ \\
\hline 2 & $120 \mathrm{~min}, 350 \mathrm{rpm}$ & - & $<1$ & $<1$ & $<1$ \\
\hline 3 & & $110{ }^{\circ} \mathrm{C}, 300 \mathrm{~W}, 30 \mathrm{~min}$ & 10 & 32 & 3 \\
\hline 4 & - & $110^{\circ} \mathrm{C}, 300 \mathrm{~W}, 60 \mathrm{~min}$ & 9 & 92 & 8 \\
\hline 5 & - & $110^{\circ} \mathrm{C}, 300 \mathrm{~W}, 120 \mathrm{~min}$ & 12 & 45 & 5 \\
\hline 6 & - & $150{ }^{\circ} \mathrm{C}, 300 \mathrm{~W}, 60 \mathrm{~min}$ & 25 & 35 & 9 \\
\hline $7^{b}$ & $60 \mathrm{~min}, 350 \mathrm{rpm}$ & $110^{\circ} \mathrm{C}, 60 \mathrm{~min}$ & $<5$ & $<1$ & $<1$ \\
\hline $8^{a}$ & $60 \mathrm{~min}, 350 \mathrm{rpm}$ & $110^{\circ} \mathrm{C}, 300 \mathrm{~W}, 60 \mathrm{~min}$ & 38 & 93 & 35 \\
\hline
\end{tabular}

Considering these results, we moved on to the use of microwave irradiation. By performing the reaction by employing $\mathrm{K}_{2} \mathrm{CO}_{3}$, under microwave irradiation, the formation of two products was observed, named as P1 and P2 [(3,4-dihydro- $2 \mathrm{H}$-benzo[b][1,4]oxazin3-yl)methanol], in Scheme 1. The influence of glycerol equivalents on the progress of the reaction was investigated. The experiments were performed under microwave irradiation at $110{ }^{\circ} \mathrm{C}$ for $1 \mathrm{~h}$. Microwave experiments displayed more promising results in comparison with the mechanochemically assisted approach. Preliminary results suggested that, by using 1 equivalent of glycerol, better results in terms of conversions were obtained, in comparison with higher glycerol equivalents. Furthermore, the influence of the catalytic system was investigated by performing the reaction in the absence of $\mathrm{K}_{2} \mathrm{CO}_{3}$. Such experiments showed a negligible conversion $(<5 \%)$, confirming the important role of the employed base. In this sense, the use of potassium carbonate could promote the carbonatation reaction between glycerol and dialkyl carbonates (in this case diethyl carbonate) and, furthermore, promote nucleophilic attack of the phenolic compound in the cyclic carbonate.

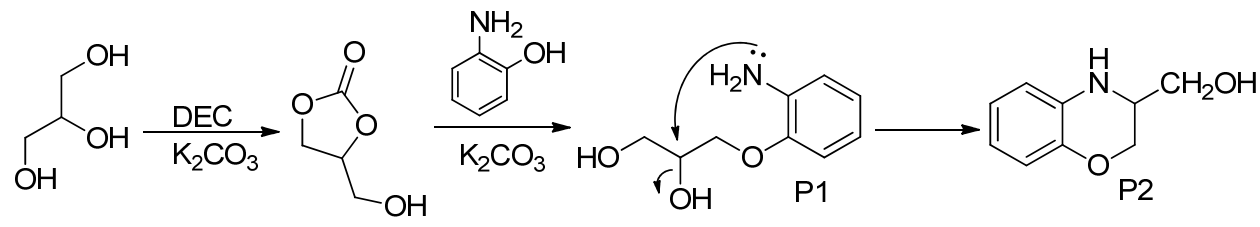

Scheme 1. Schematic representation of the reaction of 2-aminophenol and glycerol.

Moreover, the effect of time and temperature on the microwave-assisted reaction was also explored. For this purpose, several experiments were carried out considering a higher temperature $\left(150^{\circ} \mathrm{C}\right)$ and using various reaction times (30,60 and $\left.120 \mathrm{~min}\right)$ (Table 1). By performing the reaction at $110^{\circ} \mathrm{C}$, it was observed that prolonged reaction times had a negligible effect on the 2-aminophenol conversion (regardless of the reaction time, the conversion was ca. $10 \pm 2 \%$ ), while it drastically affected products selectivity (Table 1 , Entry 3-5). Such results suggest that the formation of P1 from glycerol and 2-aminophenol is a more challenging step in comparison with the formation of P2 from P1. In addition, the cyclization reaction is favored, with higher reaction times up to $60 \mathrm{~min}$ (Table 1, Entry 4). Nonetheless, at higher reaction times (120 $\mathrm{min}$ ) (Table 1, Entry 5), a reverse hydrolysis reaction could most likely take place [32], promoting a higher selectivity towards P1. In addition, by carrying out the reaction at $150{ }^{\circ} \mathrm{C}$ (Table 1, Entry 6), the conversion increased from ca. $10 \%$ to $25 \%$; however, selectivity towards P2 decreased considerably. Finally, 
the use of a higher speed during milling, in the sequential strategy, led to an increase in conversion to $46 \%$ and $57 \%$, by using $600 \mathrm{rpm}$ and $1000 \mathrm{rpm}$, respectively. Nonetheless, lower selectivities (Table S3, Exp 27-28) and, therefore, also lower yields (12\% and 4\% for the experiments performed at $600 \mathrm{rpm}$ and $1000 \mathrm{rpm}$ ) of P2 were found in both cases.

Motivated by recent studies, where the combination of milling and microwave irradiation effectively favored the progress of reactions $[33,34]$, a new set of experiments was designed by combining mechanochemical activation and microwave irradiation approaches (Table 1, Entry 8). Indeed, in addition to the energy input required in a chemical reaction, under solvent-free conditions, the mass-transport effect needs to be considered as a limiting factor $[35,36]$. In this regard, it is well-known that the kinetic energy produced during the milling gives rise to the fracture, abrasion, and refinement of the system microstructure. Consequently, the probability of contact between reagents could be enhanced and hence, mass transport limitations can be overcome $[37,38]$. By combining mechanochemical and microwave-assisted strategies, employing $\mathrm{K}_{2} \mathrm{CO}_{3}$ as catalytic system, a clear enhancement in the conversion and selectivity towards P2 was observed. Quantification analyses, according to GC results, revealed that the combined strategy (through mechanochemical activation and microwave irradiation) achieved the most promising results for the formation of P2, with conversion values of 38\% and an outstanding selectivity of $93 \%$. For comparison, the combination of milling and conventional heating was also investigated (Table 1, Entry 7, also for $1 \mathrm{~h}$ of reaction, to compare with the experiments under microwave irradiation); however, only conversions lower than 5\% were achieved.

To compare the viability of the reaction for other phenolic derivatives, the reaction was carried out using phenol instead of 2-aminophenol (glycerol: phenol ratio: 1:1). In this case, the results were more promising, resulting in a complete conversion towards the desired product, which was identified using GC-MS (Figure S1). It can be stated that the obtained fragmentation pattern agrees with the expected compound, demonstrating that this methodology proceeds satisfactorily for the selective formation of the ariloxypropanodiol product.

Importantly, the results of the reactions under microwave irradiation at higher temperatures and for longer times confirmed that the reaction methodology, following a prior mechanochemical activation, certainly resulted in a better yield in the formation of the cyclic enamine, which is also most likely economically feasible. It has been reported that the ball milling processes required less energy in comparison with microwave irradiation, due to the lower efficiency of the transformation of electrical into microwave energy $[39,40]$. It is true that, herein, the designed strategy was based on a combination of milling and microwave energy, and that such an approach could be highly competitive, in terms of energy efficiency, in comparison with conventional heating strategies previously reported for these kinds of reactions with other phenolic compounds as long reaction times of up to $28 \mathrm{~h}$ have previously been required. Herein, for comparison, the reaction of glycerol and 2-aminophenol was performed in a parallel reaction station tube. The mixture was heated to $110{ }^{\circ} \mathrm{C}$, achieving full conversion (>99\%) after $46 \mathrm{~h}$ under stirring (a conversion of $38 \%$ was reached after $38 \mathrm{~h}$ ). Such long reaction times have a direct negative impact on the energy and cost-efficiency of the process. An estimation in this regard has been included in the Supporting Information file. Atom economy and E-factor values were calculated, resulting in $82 \%$ and 2.2, respectively. In addition, and importantly, only the formation of P1 was observed, with no presence of P2, confirming the suitability of the milling-microwave sequential pathway for the selective synthesis of benzoxazine-derivatives.

The obtained MS spectrum (Figure S2) for the P1 product exhibited a molecular ion peak at $m / z 181$. In this case, it is worth noting that the lability of the hydrogen atoms in the $\mathrm{OH}$ groups could give rise to the appearance of molecular ions at $m / z[\mathrm{M}-\mathrm{H}]^{+}$and $[\mathrm{M}-2 \mathrm{H}]^{+}$; hence, the observed peak at $\mathrm{m} / z 181$ could be most likely be associated with the successful formation of 2-aminoaryloxypropanediol $(183 \mathrm{~g} / \mathrm{mol})$. Moreover, as observed in Figure S3A, the MS spectrum of the P2 peak displayed a molecular ion at $m / z 165$. Such $\mathrm{m} / \mathrm{z}$ could most likely be associated with the loss of a water molecule $(18 \mathrm{~g} / \mathrm{mol})$ from 
P1. This result could be interpreted as the intramolecular cyclization of P1, through a nucleophilic substitution of one of the hydroxyl groups by the amine group (Scheme 1). In order to corroborate the formation of $\mathrm{P} 2$, the pattern of the suspected molecule was acquired and analyzed via GC-MS (Figure S3B). Clear similarities were observed in the fragmentation pattern of both samples, which confirmed the formation of compound P2.

Moreover, the P2 product was purified by column chromatography from the reaction media, employing ciclohexane-ethylacetate (7:3) as solvent system and silica as the stationary phase. The ${ }^{1} \mathrm{H}$ and ${ }^{13} \mathrm{C}$ NMR spectra of the pure product were acquired, confirming the formation of the proposed structure for the P2 product (Figures S4 and S5). The ${ }^{13} \mathrm{C}$ NMR spectrum confirmed the presence of nine carbons, with the presence of six and three signals in the aromatic and aliphatic regions, respectively. ${ }^{13} \mathrm{C}-\mathrm{NMR}$ chemical shifts of $143.74 \mathrm{ppm}$ and $133.42 \mathrm{ppm}$ were associated with $\mathrm{C}(5)$ and $\mathrm{C}(4)$, respectively (Scheme 2). In addition, $\mathrm{C}(8)$ was assigned to the signal located at $51.23 \mathrm{ppm}$. Furthermore, ${ }^{1} \mathrm{H}$ NMR displayed the presence of a multiplet signal at $3.43 \mathrm{ppm}$, integrating one proton, which was associated with the $\mathrm{C}(8)-\mathrm{H}$ proton, strongly confirming the formation of the P2 product through the intramolecular cyclization of P1.<smiles>OC[C@H]1COc2ccccc2N1</smiles>

Scheme 2. Schematic representation and numbering of the carbon atoms in (3,4-dihydro- $2 \mathrm{H}$ benzo[b][1,4]oxazin-3-yl)methanol.

In addition, the FT-IR spectrum of P2 was acquired and is reported in Figure S6. The infrared spectrum showed a characteristic and wide band around $3369 \mathrm{~cm}^{-1}$, which can be attributed to the $\mathrm{N}-\mathrm{H}$ stretching vibrations of the $-\mathrm{NH}$ groups, most likely together with an overlapped signal that is expected for the $\mathrm{O}-\mathrm{H}$ group above $3500 \mathrm{~cm}^{-1}$. Moreover, signals located around $2938 \mathrm{~cm}^{-1}$ and $2878 \mathrm{~cm}^{-1}$ could be associated with $\mathrm{C}-\mathrm{H}$ stretching vibrations and the $\mathrm{O}-\mathrm{C}$ bond, respectively. The presence of a signal at ca. $1608 \mathrm{~cm}^{-1}$ could be attributed to N-H bend of the amine group, while the band located around $1500 \mathrm{~cm}^{-1}$ could be assigned to the $\mathrm{C}-\mathrm{C}$ stretching vibration in the aromatic rings. Furthermore, the bands observed around $1436 \mathrm{~cm}^{-1}$ and $1360 \mathrm{~cm}^{-1}$ could be attributed to the $\mathrm{C}-\mathrm{H}$ bend and the C-H rock of alkanes. Significantly, the peaks appearing at $1279 \mathrm{~cm}^{-1}$ and $1207 \mathrm{~cm}^{-1}$ can be attributed to the $\mathrm{C}-\mathrm{O}$ stretching vibrations of alcohols and to the $\mathrm{C}-\mathrm{N}$ stretching vibrations of amines, respectively, also supporting the formation of P2. Moreover, FT-IR analysis of P1 was also acquired (Figure S7), revealing a similar pattern, according to the expected similarities between the P1 and P2 structures. It is worth highlighting the clear difference observed for the bands above $3000 \mathrm{~cm}^{-1}$. In the case of $\mathrm{P} 1$, a wider signal could be observed, most likely due to the contribution of the two hydroxyl groups. In addition, it is well-known that, for primary amines $\left(\mathrm{RNH}_{2}\right)$, two signals could be observed in the region above $3000 \mathrm{~cm}^{-1}$, namely the asymmetrical $\mathrm{N}-\mathrm{H}$ stretch and the symmetrical $\mathrm{N}-\mathrm{H}$ stretch, while only one signal related to NH group appears in the spectrum for secondary amines. Indeed, the obtained spectra are in accordance with the expected aforementioned results, since as could be observed for $\mathrm{P} 1$, there was a presence of two peaks within the wide band above $3000 \mathrm{~cm}^{-1}$.

\section{Materials and Methods}

Several strategies for the glycerol valorization have been considered, as described below.

\subsection{Mechanochemically-Assisted Approach}

A set of experiments was designed considering glycerol equivalents, milling time, and speed, as shown in Table S1. The reactions were carried out in ball mill reactors (Retsch 
PM100 ball mill model, Retsch Emax ball mill model) (Retsch, Düsseldorf, Germany), using a $125 \mathrm{~mL}$ reaction chamber and $60 \mathrm{~g}$ of $2 \mathrm{~mm}$ stainless steel balls.

\subsection{Microwave-Assisted Approach}

The reactions were performed employing the same reactants concentrations, varying the glycerol equivalents from 1 to 3 . The experiments were performed under microwave irradiation in a CEM-Discover microwave reactor (CEM, Matthews, NC, USA), equipped with a PC-controlled interface, at $110^{\circ} \mathrm{C}$, for $1 \mathrm{~h}$, employing a maximum power of $300 \mathrm{~W}$ and a maximum pressure of 240 bars (Table S2).

\subsection{Combined Microwave and Mechanochemical-Assisted Approach}

A set of experiments was designed, combining mechanochemical activation and microwave irradiation approaches (Table S3).

The conversion, selectivity, and yield were investigated using gas chromatography (GC) in an Agilent 6890N gas chromatograph (Agilent, Santa Clara, CA, USA) (60 mL min ${ }^{-1}$ $\mathrm{N}_{2}$ carrier flow, 20 psi column top head pressure) using a flame ionization detector (FID). An HP-5 capillary column $(30 \mathrm{~m} \times 0.32 \mathrm{~mm} \times 0.25 \mathrm{~mm})$ was employed. In addition, the collected liquid samples were analyzed using GC-MS using an Agilent 7820A GC/5977B High Efficiency Source (HES) MSD (Agilent, Santa Clara, CA, USA), in order to identify the obtained products. Moreover, the P2 product was purified by column chromatography, employing ciclohexane-ethylacetate (7:3) as the solvent system and silica as the stationary phase. Additionally, the ${ }^{1} \mathrm{H}$ and ${ }^{13} \mathrm{C}-\mathrm{NMR}$ spectra were determined using a Bruker Avance III HD $400 \mathrm{WB}$ equipped with a $4 \mathrm{~mm} \mathrm{CP} / \mathrm{MAS}$ probe, employing deuterated methanol.

Atom economy and E-factor values were calculated according to Equations (1) and (2).

$$
\begin{gathered}
\text { Atom economy }=\frac{\text { Molecular mass of product } P 2}{\text { Molecular masses of reactants }} \times 100 \\
E-\text { factor }=\frac{\text { Mass of total waste }}{\text { Mass of product } P 2}
\end{gathered}
$$

\section{Conclusions}

The use of novel technologies could lead to more sustainable scenarios for organic chemistry, giving rise to environmentally friendly industrial processes. In this work, the combination of milling, microwave technologies, and solvent-less conditions were explored for the valorization of glycerol towards a benzoxaxine derivative. Mechanochemical protocols could improve the contact between the reagents and favor mass-transport, while microwave irradiation leads to lower reaction times. This contribution could create new possibilities for the design of sustainable processes, helping the recognition of mechanical energy and its possible combination with other approaches for organic synthesis and for boosting products yields. As suggested by the estimation of energy usage, the present methodology could be competitive in comparison to conventional protocols, but more insightful and case-to-case research should be performed.

Supplementary Materials: The following supporting information can be downloaded, Figure S1: Comparison of MS-spectra (A) MS-spectrum of the product from the reaction employing phenol, instead of 2-aminophenol. (B) MS-spectrum reported in the NIST library; Figure S2: MS-spectrum of the obtained product by employing $\mathrm{K}_{2} \mathrm{CO}_{3}$, appearing at retention time of $11.8 \mathrm{~min}$ in the chromatograms. Figure S3: Comparison of MS-spectra of the product from the reaction, at retention time ca. $16 \mathrm{~min}$, and the commercial pattern. (A) MS-spectrum of the obtained product by employing $\mathrm{K}_{2} \mathrm{CO}_{3}$, appearing at retention time of $16.7 \mathrm{~min}$ in the chromatograms. (B) MS-spectrum of the commercial pattern; Figure S4: ${ }^{1} \mathrm{H}-\mathrm{NMR}$-spectrum of the purified product, appearing at retention time of $16.7 \mathrm{~min}$ in the chromatograms; Figure S5: ${ }^{13} \mathrm{C}-\mathrm{NMR}$-spectrum of the purified product, appearing at retention time of $16.7 \mathrm{~min}$ in the chromatograms; Figure S6: FT-IR spectrum of the purified product P2, appearing at retention time of $16.7 \mathrm{~min}$ in the chromatograms; Figure S7: FT-IR spectrum of the 
purified product P1, appearing at retention time of $11.7 \mathrm{~min}$ in the chromatograms. Table S1: Set of experiments under ball milling conditions; Table S2: Set of experiments under microwave-assisted conditions; Table S3: Set of experiments under microwave and mechanochemical-assisted conditions.

Author Contributions: Conceptualization, D.R.-P., R.L. and C.E.; methodology, M.S. and A.P. validation, C.E., R.L., S.M.O. and A.A.R.R.; formal analysis, A.A.R.R.; investigation, M.Á.T.-P. and D.R.-P.; resources, R.L. and C.E.; data curation, A.A.R.R.; writing—original draft preparation, D.R.-P.; writing-review and editing, R.L., S.M.O., A.P., M.S., A.A.R.R.; visualization, C.E.; supervision, R.L.; project administration, R.L.; funding acquisition, R.L. All authors have read and agreed to the published version of the manuscript.

Funding: This research received the support of MINECO for funding under project PID2019109953GB-I00, co-financed with FEDER funds, also from Junta de Andalucia for funding under project P18-RT-4576. This work has been supported by the Researchers Supporting Project number (RSP-2021/405), King Saud University, Saudi Arabia.

Institutional Review Board Statement: Not applicable.

Informed Consent Statement: Not applicable.

Data Availability Statement: Not applicable.

Acknowledgments: Rafael Luque gratefully acknowledges MINECO for funding under project PID2019-109953GB-I00, co-financed with FEDER funds. R.L. also gratefully acknowledges funding from Consejeria de Ciencia e Innovacion, Junta de Andalucia for funding under project P18-RT4576. This work has been supported by the Researchers Supporting Project number (RSP-2021/405), King Saud University, Saudi Arabia. This publication has been supported by RUDN University Strategic Academic Leadership Program (R. Luque). D.R.P gratefully acknowledges the support of COST-Action CA18112 "Mechanochemistry for sustainable industry" and of Progetto INTEP from Università di Messina.

Conflicts of Interest: The authors declare no conflict of interest.

Sample Availability: Samples of the compounds are not available from the authors.

\section{References}

1. Xu, C.; Paone, E.; Rodríguez-Padrón, D.; Luque, R.; Mauriello, F. Recent catalytic routes for the preparation and the upgrading of biomass derived furfural and 5-hydroxymethylfurfural. Chem. Soc. Rev. 2020, 49, 4273-4306. [CrossRef]

2. Rodríguez-Padrón, D.; Puente-Santiago, A.R.; Balu, A.M.; Muñoz-Batista, M.J.; Luque, R. Environmental Catalysis: Present and Future. Chem. Cat. Chem. 2019, 11, 18-38. [CrossRef]

3. Tokarska, K.B.; Stolpe, M.B.; Sippel, S.; Fischer, E.M.; Smith, C.J.; Lehner, F.; Knutti, R. Past warming trend constrains future warming in CMIP6 models. Sci. Adv. 2020, 6, eaaz9549. [CrossRef] [PubMed]

4. Liu, Y.; Lyu, Y.; Tian, J.; Zhao, J.; Ye, N.; Zhang, Y.; Chen, L. Review of waste biorefinery development towards a circular economy: From the perspective of a life cycle assessment. Renew. Sustain. Energy Rev. 2021, 139, 110716. [CrossRef]

5. Liao, Y.; Koelewijn, S.-F.; Bossche, G.V.d.; Aelst, J.V.; Bosch, S.V.d.; Renders, T.; Navare, K.; Nicolaï, T.; Aelst, K.V.; Maesen, M.; et al. A sustainable wood biorefinery for low-carbon footprint chemicals production. Science 2020, 367, 1385-1390. [CrossRef] [PubMed]

6. Paone, E.; Tabanelli, T.; Mauriello, F. The rise of lignin biorefinery. Curr. Opin. Green Sustain. Chem. 2020, 24, 1-6. [CrossRef]

7. Benessere, V.; Cucciolito, M.E.; De Santis, A.; Di Serio, M.; Esposito, R.; Melchiorre, M.; Nugnes, F.; Paduano, L.; Ruffo, F. A Sustainable Process for the Production of Varnishes Based on Pelargonic Acid Esters. J. Am. Oil Chem. Soc. 2019, 96, 443-451. [CrossRef]

8. Melchiorre, M.; Amendola, R.; Benessere, V.; Cucciolito, M.E.; Ruffo, F.; Esposito, R. Solvent-free transesterification of methyl levulinate and esterification of levulinic acid catalyzed by a homogeneous iron(III) dimer complex. Mol. Catal. 2020, $483,110777$. [CrossRef]

9. Melchiorre, M.; Benessere, V.; Cucciolito, M.E.; Melchiorre, C.; Ruffo, F.; Esposito, R. Direct and Solvent-Free Oxidative Cleavage of Double Bonds in High-Oleic Vegetable Oils. Chem. Select 2020, 5, 1396-1400. [CrossRef]

10. Khodadadi, M.R.; Malpartida, I.; Tsang, C.-W.; Lin, C.S.K.; Len, C. Recent advances on the catalytic conversion of waste cooking oil. Mol. Catal. 2020, 494, 111128. [CrossRef]

11. Essamlali, Y.; Amadine, O.; Larzek, M.; Len, C.; Zahouily, M. Sodium modified hydroxyapatite: Highly efficient and stable solid-base catalyst for biodiesel production. Energy Convers. Manag. 2017, 149, 355-367. [CrossRef]

12. Varma, R.S.; Len, C. Glycerol valorization under continuous flow conditions-recent advances. Curr. Opin. Green Sustain. Chem. 2019, 15, 83-90. [CrossRef] 
13. Corrêa, I.; Faria, R.P.V.; Rodrigues, A.E. Continuous Valorization of Glycerol into Solketal: Recent Advances on Catalysts, Processes, and Industrial Perspectives. Sustain. Chem. 2021, 2, 286-324. [CrossRef]

14. Aroua, M.K.; Cognet, P. Editorial: From Glycerol to Value-Added Products. Front. Chem. 2020, 8, 69. [CrossRef]

15. Akinnawo, C.A.; Mosia, L.; Alimi, O.A.; Oseghale, C.O.; Fapojuwo, D.P.; Bingwa, N.; Meijboom, R. Eco-friendly synthesis of valuable fuel bio-additives from glycerol. Catal. Commun. 2021, 152, 106287. [CrossRef]

16. Kostyniuk, A.; Bajec, D.; Djinović, P.; Likozar, B. One-step synthesis of glycidol from glycerol in a gas-phase packed-bed continuous flow reactor over HZSM-5 zeolite catalysts modified by $\mathrm{CsNO}_{3}$. Chem. Eng. J. 2020, 394, 124945. [CrossRef]

17. Arora, S.; Gosu, V.; Kumar, U.K.A.; Subbaramaiah, V. Valorization of glycerol into glycerol carbonate using the stable heterogeneous catalyst of Li/MCM-41. J. Clean. Prod. 2021, 295, 126437. [CrossRef]

18. Bartoli, M.; Zhu, C.; Chae, M.; Bressler, D.C. Glycerol Acetylation Mediated by Thermally Hydrolysed Biosolids-Based Material. Catalysts 2020, 10, 5. [CrossRef]

19. Cornejo, A.; Barrio, I.; Campoy, M.; Lázaro, J.; Navarrete, B. Oxygenated fuel additives from glycerol valorization. Main production pathways and effects on fuel properties and engine performance: A critical review. Renew. Sustain. Energy Rev. 2017, 79, 1400-1413. [CrossRef]

20. Truscello, A.M.; Gambarotti, C.; Lauria, M.; Auricchio, S.; Leonardi, G.; Shisodia, S.U.; Citterio, A. One-pot synthesis of aryloxypropanediols from glycerol: Towards valuable chemicals from renewable sources. Green Chem. 2013, 15, 625-628. [CrossRef]

21. Garg, V.; Kumar, A.; Chaudhary, A.; Agrawal, S.; Tomar, P.; Sreenivasan, K.K. Synthesis, biological evaluation and molecular docking studies of 1,3-benzoxazine derivatives as potential anticancer agents. Med. Chem. Res. 2013, 22, 5256-5266. [CrossRef]

22. Nomanbhay, S.; Ong, M.Y. A Review of Microwave-Assisted Reactions for Biodiesel Production. Bioengineering $2017,4,57$. [CrossRef]

23. Kokel, A.; Schäfer, C.; Török, B. Application of microwave-assisted heterogeneous catalysis in sustainable synthesis design. Green Chem. 2017, 19, 3729-3751. [CrossRef]

24. Friščić, T.; Mottillo, C.; Titi, H.M. Mechanochemistry for Synthesis. Angew. Chem. Int. Ed. 2020, 59, 1018-1029. [CrossRef]

25. Andersen, J.; Mack, J. Mechanochemistry and organic synthesis: From mystical to practical. Green Chem. 2018, 20, 1435-1443. [CrossRef]

26. Tan, D.; García, F. Main group mechanochemistry: From curiosity to established protocols. Chem. Soc. Rev. 2019, 48, 2274-2292. [CrossRef] [PubMed]

27. Muñoz-Batista, M.J.; Rodriguez-Padron, D.; Puente-Santiago, A.R.; Luque, R. Mechanochemistry: Toward Sustainable Design of Advanced Nanomaterials for Electrochemical Energy Storage and Catalytic Applications. ACS Sustain. Chem. Eng. 2018, 6, 9530-9544. [CrossRef]

28. Seo, T.; Ishiyama, T.; Kubota, K.; Ito, H. Solid-state Suzuki-Miyaura cross-coupling reactions: Olefin-accelerated C-C coupling using mechanochemistry. Chem. Sci. 2019, 10, 8202-8210. [CrossRef]

29. Yeboue, Y.; Jean, M.; Subra, G.; Martinez, J.; Lamaty, F.; Métro, T.-X. Epimerization-Free C-Term Activation of Peptide Fragments by Ball Milling. Org. Lett. 2021, 23, 631-635. [CrossRef] [PubMed]

30. Thorpe, J.D.; O’Reilly, D.; Friščić, T.; Damha, M.J. Mechanochemical Synthesis of Short DNA Fragments. Chem. Eur. J. 2020, 26, 8857-8861. [CrossRef] [PubMed]

31. Espro, C.; Rodríguez-Padrón, D. Re-thinking organic synthesis: Mechanochemistry as a greener approach. Curr. Opin. Green Sustain. Chem. 2021, 30, 100478. [CrossRef]

32. Bernasconi, C.F.; Howard, K.A.; Kanavarioti, A. Nucleophilic addition to olefins. 11. Kinetics of the reversible hydrolysis of benzylidenemalononitrile in water. J. Am. Chem. Soc. 1984, 106, 6827-6835. [CrossRef]

33. Franco, A.; De, S.; Balu, A.M.; Romero, A.A.; Luque, R. Integrated Mechanochemical/Microwave-Assisted Approach for the Synthesis of Biogenic Silica-Based Catalysts from Rice Husk Waste. ACS Sustain. Chem. Eng. 2018, 6, 11555-11562. [CrossRef]

34. Polshettiwar, V.; Varma, R.S. ChemInform Abstract: Environmentally Benign Chemical Synthesis via Mechanochemical Mixing and Microwave Irradiation; RSC Publishing: Cambridge, UK, 2010; Volume 41. [CrossRef]

35. Guérin, B.; Fernandes, D.M.; Daran, J.-C.; Agustin, D.; Poli, R. Investigation of induction times, activity, selectivity, interface and mass transport in solvent-free epoxidation by $\mathrm{H}_{2} \mathrm{O}_{2}$ and TBHP: A study with organic salts of the $\left[\mathrm{PMo}_{12} \mathrm{O}_{40}\right]^{3-}$ anion. New J. Chem. 2013, 37, 3466-3475. [CrossRef]

36. Gervais, T.; Jensen, K.F. Mass transport and surface reactions in microfluidic systems. Chem. Eng. Sci. 2006, 61, 1102-1121. [CrossRef]

37. Michalchuk, A.A.L.; Tumanov, I.A.; Boldyreva, E.V. The effect of ball mass on the mechanochemical transformation of a single-component organic system: Anhydrous caffeine. J. Mater. Sci 2018, 53, 13380-13389. [CrossRef]

38. Howard, J.L.; Cao, Q.; Browne, D.L. Mechanochemistry as an emerging tool for molecular synthesis: What can it offer? Chem. Sci. 2018, 9, 3080-3094. [CrossRef]

39. Baig, R.B.N.; Varma, R.S. Alternative energy input: Mechanochemical, microwave and ultrasound-assisted organic synthesis. Chem. Soc. Rev. 2012, 41, 1559-1584. [CrossRef]

40. Ribeiro, A.P.C.; Alegria, E.C.B.A.; Kopylovich, M.N.; Ferraria, A.M.; Botelho do Rego, A.M.; Pombeiro, A.J.L. Comparison of microwave and mechanochemical energy inputs in the catalytic oxidation of cyclohexane. Dalton Trans. 2018, 47, 8193-8198. [CrossRef] 